\title{
ESTÉTICA, ÉTICA E POLÍTICA: EM TORNO DA QUESTÃO DO TRABALHO NO SEGUNDO NIETZSCHE.
}

\author{
Ernani Chaves \\ Universidade Federal do Pará
}

\begin{abstract}
From the writings of the so-called second phase of the Nietzsche's thought I intend to show the aesthetical, ethical and political implications concerning the value analysis of work in modern societies of the industrial era. In several aphorisms, Nietzsche indicates, analyzes and takes several consequences of the moral value attributed to work, specially associating to the age denominated by him "machine culture" the principles of moral utilitarianism. In the political field, we could say that Nietzsche fits into the tradition of romantic anticapitalism, because while acknowledging the harmful consequences of this moral valuation of work, he finds in the work no emancipative value, always considering a certain form of leisure, as the effective resistance to the exploitation by work.
\end{abstract}

Keywords: work, art, leisure, utilitarianism, romantic anticapitalism.

Resumo: A partir dos escritos da chamada segunda fase do pensamento de Nietzsche, pretendo mostrar as implicações estéticas, éticas e políticas, concernentes à análise do valor do trabalho nas sociedades modernas da era industrial. Em diversos aforismos, Nietzsche indica, analisa e tira diferentes conseqüências do valor moral atribuído ao trabalho, em especial associando à época denominada por ele de "cultura da máquina" os princípios do utilitarismo moral. No campo político, poderíamos dizer que Nietzsche se inscreve na tradição do anticapitalismo romântico, pois embora reconheça as danosas conseqüências dessa valoração moral do trabalho, não encontra no trabalho nenhum valor emancipatório, considerando sempre uma certa forma de ócio, como a efetiva resistência à exploração pelo trabalho.

Palavras-chave: trabalho, arte, ócio, utilitarismo, anticapitalismo romântico. 
Este artigo tem como objetivo apontar o quanto algumas questões relativas à função e ao lugar do trabalho nas sociedades modernas, são fundamentais para compreender temas decisivos do pensamento de Nietzsche, nos quais se entrelaçam e se articulam questões relativas à estética, mas também à ética e à política. Em relação a estes temas, tendo em vista o primeiro Nietzsche, encontramos na recepção brasileira o excelente artigo de Anna Hartmann Cavalcanti (2007), que toma como objeto de seu estudo, o primeiro Nietzsche. Neste artigo, a partir de uma análise minuciosa e rigorosa de dois pequenos ensaios de Nietzsche, "O estado grego" e "A disputa em Homero", a autora nos mostra o quanto uma leitura atenta destes ensaios nos permite compreender não apenas o alvo político de Nietzsche, poderíamos assim dizer, qual seja, a nossa modernidade política, mas também a sua perspectiva metodológica, que eu chamaria de anti-historicista, consistindo na comparação entre estado moderno e estado grego. $\mathrm{O}$ resultado dessas análises mostra os equívocos quando lemos a crítica de Nietzsche à "dignidade do trabalho" ou ainda as suas observações acerca do papel ambíguo da escravidão, descoladas da sua crítica devastadora ao estado moderno. Recomendo vivamente aos interessados por este tema a leitura do artigo de Anna Hartmann e se parto dele é porque ele se encontra no horizonte das reflexões que pretendo desenvolver aqui, embora com um deslocamento importante, na medida em que meu interesse se concentra nos livros da segunda fase do pensamento de Nietzsche. Parece que neste momento de sua obra, Nietzsche incorporou publicamente de maneira decisiva e definitiva as questões relativas ao trabalho, que haviam permanecido na sua fase juvenil, de algum modo, no âmbito privado. Refiro-me ao fato de que tanto "O estado grego" quanto "A disputa em Homero" foram reunidos pelo próprio Nietzsche em um livro que jamais foi publicado, pois se tratava, na verdade, de um presente a Cosima Wagner no Natal de 1872 e que ele intitulou, de forma bem emblemática, "Cinco prefácios a cinco livros não escritos". Isto não significa, para o próprio Nietzsche, que suas reflexões juvenis ficaram definitivamente para trás. Muito pelo contrário, é justamente por já ter se despedido da sua "metafísica de artista" (é assim que ele chamará, no "Prefácio" de 1886 ao Nascimento da tragédia, o seu esforço de compreensão da tragédia grega, para além de Schopenhauer e Wagner), que Nietzsche poderá, agora, apresentar publicamente sua crítica a um mundo dominado pela idéia de que o trabalho dignifica a vida, de que é ele quem 
dá sentido à existência humana, mesmo que agora o contraponto com a cultura grega tenha ficado em segundo plano, em favor de outro momento na história dos processos de trabalho, mais especialmente nos processos artesanais, pré-capitalistas, que se desenvolvem a partir da Idade Média. Não por acaso, no §220, de "O Andarilho e sua sombra", no segundo livro de Humano, demasiado humano, intitulado "Reação à cultura da máquina", Nietzsche caracterizará a nossa época, justamente, como a época da "cultura da máquina" (KSA, 2, p. 653). ${ }^{1}$

A idéia de uma "época da cultura da máquina" é um mote valioso para minhas pretensões. O tema do $§ 220$ do "Andarilho", acima citado, fora anunciado, um pouco antes, no $\$ 218$ do mesmo livro, que se chama, por sua vez, "A máquina como mestra". Como sabemos, a invenção das máquinas caracterizam a chamada "Revolução Industrial" do século XIX, contribuindo decisivamente para o processo acelerado de industrialização, que no caso da Alemanha a fez passar de maneira muito mais rápida e por isso mesmo muito mais violenta do que na Inglaterra e na França, ao império do modo de produção capitalista, para utilizarmos o conceito consagrado nas análises de Marx. A Karl Löwith, primeiro grande comentador das análises de Nietzsche sobre o trabalho, não escapou este conjunto de profundas transformações na história do ocidente, que fizeram coincidir no século XIX, o advento da máquina e a definitiva valorização do trabalho como aquilo que dá sentido à existência. Neste diapasão, escreve Löwith: "O homem da época burguesa sente não apenas a obrigação, mas a vontade de trabalhar, pois uma vida sem trabalho não lhe parece digna de ser vivida, ela lhe parece vã" (1969, p. 319). Ora, na contracorrente da avaliação moralmente positiva concedida ao trabalho em sua época, Nietzsche vai chamar atenção para o fato de que a relação homem-máquina se estabelece de uma forma que não favorece aos processos criativos, aos processos artísticos por excelência. Ao contrário, esta relação tem o objetivo de organizar a multidão, uma vez que este ordenamento significa a realização de "operações em que cada um só tem de fazer uma coisa". Assim sendo, ao contrário dos ideais de sua época, Nietzsche vai insistir em

\footnotetext{
${ }^{1}$ As citações de obras de Nietzsche serão feitas a partir da edição crítica de Colli e Montinari (KSA), seguidas do número do volume e da página. As traduções brasileiras utilizadas são referenciadas ao final. Sempre que julgar necessário, as modifico.
} 
dizer que a máquina é que domina o homem e não o inverso. E este domínio, que se inicia na fábrica, se expande e se desenvolve para além dela, em especial na "organização de partido e na condução de guerra". Dessa maneira, a fábrica, o partido político e a defesa dos interesses nacionais por meio da guerra, constituem os esteios nos quais se firmam a transformação da máquina em "mestra", de tal modo que a "soberania individual" desaparece, dando lugar apenas à uniformidade, não havendo mais lugar para a exceção, a singularidade ou ainda, usando uma terminologia do primeiro Nietzsche, não havendo mais lugar para o gênio. A mestra-máquina ensina, fundamentalmente, o valor da "centralização", como o resultado da transformação do indivíduo em "uma ferramenta (Werkzeug) para uma meta (Zwecke)". Trata-se, portanto, na era da máquina, do império do um e da uniformidade ${ }^{2}$, uma época que se caracteriza ao mesmo tempo pelo excesso de trabalho. Já em um fragmento póstumo de outubro-dezembro de 1876, isto é, três anos antes da redação final de "O Andarilho e sua sombra", Nietzsche anotava o seguinte a este respeito: "Os operários (die Arbeiter) lamentam que trabalham demais. Mas, o mesmo excesso de trabalho se encontra em todo lugar, entre os comerciários, intelectuais, funcionários, militares: na classe rica este excesso aparece como impulso interior (innerer Trieb) da atividade em demasia, entre os operários este impulso é forçado a se exteriorizar, esta é a diferença" (Frag. Póst. 19[21] KSA, 8, p. 335). Trata-se, portanto, de considerar a diferença entre as "ferramentas": para a classe rica, trata-se de mera expressão de um impulso interno, como se neste caso trabalhar em excesso fosse uma imperiosa necessidade, uma expressão da própria natureza; para os operários, ao contrário, trata-se tão somente de um impulso coercitivo, que para ser benéfico de algum modo precisa ser atenuado. É por isso que este fragmento conclui que o "operário não pode

\footnotetext{
2 Em julho de 1879, Nietzsche fará a seguinte anotação acerca da "meta" (Zwecke): "Devido à meta a vida torna-se inteiramente sem sentido e falsa. Trabalha-se para se alimentar? Vive-se para deixar filhos (ou obras). Este de todo modo - etc. e finalmente salto mortale. Muito mais no trabalho o fim (das Ende) é sempre comer etc.: com a meta acoplamos 2 fins. Como para comer e para viver, ou seja, para comer de novo" (Frag. Póst. 41[5], KSA, 8, p.585). Um pouco depois, em julho-agosto de 1879, Nietzsche relaciona a meta da vida como nutrição, alimentação, com as metas morais: "Necessitamos de alimentação: mas as necessidades de nosso gosto são outras, primeiro coação (Zwang), depois hábito (Gewöhnung), então prazer (Lust), os quais sempre desejam repetir-se (Necessidade). Igual ao sentido moral, que também é tão diferente com o gustus, mas a meta que ele oferece é quase a mesma (Sustentar as pessoas devido e contra elas" (Frag. Póst. 42[15], KSA, 8, p. 598).
} 
acreditar que o banqueiro atual desfrute mais e com mais dignidade a vida do que ele", constituindo assim mais um antagonismo no interior da era da máquina, antagonismo ao mesmo tempo moral e político, uma vez que está ditado pela diferença entre necessidade e coerção.

Corroborando estas idéias, mas levando-as a um ponto extremo e radical, o $\$ 220$ desloca e desdobra o antagonismo apresentado no $\$ 218$. Neste, o homem, criador das máquinas, não mais as domina; ao contrário, torna-se um escravo delas. Naquele, o processo de dominação técnico e tecnológico, que inverte as relações entre criador e criatura, vê desvelado seu fundamento. $\mathrm{O}$ antagonismo agora é outro: embora produto de um enorme esforço intelectual, esforço de pensamento, a máquina, ao final deste processo, destrói o pensamento, na medida em que "põe em movimento, nas pessoas que a utilizam, quase que só as energias inferiores, sem pensamento". Com isso, a cultura da máquina não impulsiona as atividades mais elevadas, como a atividade artística, e todo o seu sentido de ação e atividade deve redundar na uniformização.

Esta relação, na qual o homem acaba como "escravo" da máquina aparece com todas as letras em um fragmento póstumo de Junho-Julho de 1879, do mesmo modo que Nietzsche aponta para possibilidades de resistência: "A máquina controla terrivelmente, de tal modo que tudo acontece certo e no tempo certo. $\mathrm{O}$ trabalhador obedece ao déspota cego, ele é mais do que seu escravo. A máquina não educa no sentido da vontade de autodomínio. Ela desperta o anseio de reação contra o despotismo - a desordem, a loucura, o êxtase. A máquina clama pelas Saturnálias" (KSA, 8 , p. 579). Com base nestas observações, retorno ao $\$ 170$, ainda em "O Andarilho e sua sombra", intitulado "A arte na época do trabalho".

Anterior a todos os aforismos citados anteriormente, o $§ 170$, entretanto, só pode ser percebido em sua radical dimensão, na medida em que o colocamos em diálogo com estes outros aforismos, que lhes são posteriores na organização do livro. Este aforismo tem como pano de fundo a crítica a Wagner. Ele pode ser interpretado, de início, como uma resposta a uma afirmação do próprio Nietzsche no prefácio à primeira edição do Nascimento da tragédia, dedicado, justamente, a Wagner. Ali, já antecipando de alguma forma as severas críticas que seriam dirigidas ao livro, ele chamava atenção para o fato de que seu livro poderia ser criticado por levar "um problema estético tão a sério", tendo em vista a "seriedade da existência" e isso se devia, por sua vez, ao fato de que não se podia 
facilmente reconhecer na arte algo mais do que "um divertido acessório, um tintinar de guizos". Em prévia resposta a estes críticos, Nietzsche afirmava, por sua vez, que "a arte é a tarefa suprema e a atividade propriamente metafísica desta vida”. Sim, é possível ainda dizer que Nietzsche, na sua segunda fase, continua atribuindo à arte este mesmo lugar, esta mesma condição. Mas, não é mais possível alinhá-la a uma metafísica, mesmo que de artista, para reconhecer o seu valor de atividade suprema. E, igualmente, não se pode mais encontrar em Wagner a esperança do ressurgimento do espírito da tragédia grega na modernidade, justamente porque - e eis aqui o ponto essencial - a arte wagneriana não é mais considerada inteiramente oposta a uma redução da arte aos fins utilitários próprios da época da “cultura da máquina", ou seja, ao "divertimento acessório".

Ora, o $\$ 170$ caracteriza a nossa época como uma "época laboriosa" (arbeitsamen Zeitalters) e nesta perspectiva mesmo a maior e mais importante expressão artística só é legítima na medida em que se relaciona ao "tempo livre" (Musse) e ao "descanso" (Erholung). Como conseqüência disso, escreve Nietzsche: "Este é o fato mais geral que alterou a posição da arte diante da vida: ao fazer grandes exigências de tempo e energia aos seus receptores, ela tem contra si a consciência dos laboriosos e capazes, é dirigida aos indolentes e sem consciência, que, no entanto, em conformidade com sua natureza, não têm ligação justamente com a grande arte e vêem as exigências desta como pretensões".

Podemos ver como, passo a passo, esta passagem refaz àquela do prefácio a Wagner no Nascimento da tragédia, ou seja, seu ponto de partida não é mais a incondicional unidade entre arte e vida, mas, ao contrário, aponta para o descompasso, para o desacerto entre ambas, na medida em que a vida passa a estar submetida aos imperativos do mundo do trabalho. Em outras palavras, a valoração moral do trabalho se torna agora um ponto de referência essencial no processo de hierarquização dos valores. E é exatamente por isso que as expressões artísticas, mesmo as mais elevadas, vão se modelar de acordo com a valorização moral do trabalho. E assim, a "grande arte" (grosse Kunst), cada vez mais sucumbe a um processo de "aviltamento" e "travestimento", cedendo espaço cada vez mais à "pequena arte" (kleine Kunst), a qual já está inteiramente adaptada como "arte do descanso, da divertida recreação". Este processo se radicaliza a tal ponto que a "grande arte" passa também a assumir para si as características da "pequena arte" e os grandes artistas também passam a prometer "repouso e 
distração" aos homens cansados do trabalho, "de modo igual aos artistas de entretenimento, que se satisfazem em obter uma vitória sobre o cenho franzino e os olhos fundos".

Esta adaptação não se faria, pensa Nietzsche, de uma forma tão difícil, uma vez que os grandes artistas, bem mais que os pequenos sabem manipular com maestria (leia-se Wagner!) os artifícios que permitem excitar, estimular e seduzir as massas que enchiam os teatros após um dia exaustivo de trabalho. Assim, quase que desaparecia integralmente a distinção que um fragmento póstumo de outubro-dezembro de 1876 ainda fazia entre o artista e o trabalhador, chamado por Nietzsche neste fragmento de "homem de ação" (der Thätige): "O homem de ação quer se divertir (zerstreuen) por meio da arte, o artista almeja a mais elevada concentração (Sammlung). Em consequência disso, eles são insatisfeitos um com o outro e se aferram um no outro. De todo modo, a arte não é para esses homens de ação, mas para aqueles que têm excesso de tempo livre (Musse) e por isso podem presentear, excepcionalmente, sua mais elevada seriedade ao artista: para a existência dessa classe de Olímpios $^{3}$ ociosos, esses homens de ação (sejam eles trabalhadores ou banqueiros ou funcionários públicos) devem se preocupar com seu excesso de trabalho (Überarbeit). A existência dessa classe [de Olímpios] é um mal (Übel), de tal modo que a arte também é um mal. Arte é a atividade dos ociosos. Prazeres constituem o ócio dos homens de ação". (KSA, 8, p. 337) ${ }^{4}$. É como se toda a reflexão posterior de Nietzsche nesta época fosse numa direção contrária, ou seja, para mostrar que só havia uma possibilidade para este artista cultivador de uma espécie de ócio ainda poder ser chamado de artista, qual seja, a de se adaptar às exigências do mundo do trabalho. É como se Nietzsche estivesse, a sua maneira, falando da perda da "aura" das obras de arte. O que não significa

\footnotetext{
${ }^{3}$ Referência ao compositor frígio do século VII a.C., referido, por exemplo no $1340^{a}$, do cap. V, Livro VIII da Política, de Aristóteles.

4 Importa chamar atenção para o uso que Nietzsche faz da palavra "Muss" e seus derivados, como "Müssigang". Ora, "Muss" é o "tempo livre" depois do trabalho, comprometido, entretanto, com a reposição das forças dispendidas no trabalho por meio dos espetáculos que garantem a diversão, ora equipara-se à palavra latina "Otium", para designar a "ociosidade" no seu sentido positivo, como uma espécie de suspensão do tempo cotidiano, permitindo a abertura às atividades do espírito ou ainda as artísticas. Ou ainda, como acontece na passagem do fragmento póstumo que ora comento, equivalente a "ócio", mas tendo um sentido diverso, seja para o artista, como estímulo, impulso à criação, seja para o "homem de ação", funcionando agora como busca do prazer em meio às exigências do mundo do trabalho.
} 
que, para ele, esse processo de "perda da aura" tenha as mesmas conseqüências indicadas, algumas décadas depois, nas célebres análises de Walter Benjamin. Se formos levar ainda mais longe uma comparação entre Nietzsche e os chamados "frankfurtianos", diríamos que Nietzsche estaria muito mais próximo do conceito de "indústria cultural", de Adorno e Horkheimer, os quais vão também denunciar a transformação da arte em mero divertimento para as massas, do que de Benjamin, que procede em vários aspectos numa direção contrária, na medida em que vai dar outra interpretação às idéias de distração e diversão. De todo modo, encontramos nestes aforismos, em pleno processo, o exercício do Nietzsche psicólogo das profundezas, que munido de um sismógrafo, procura captar os profundos abalos ocorridos tanto no processo de criação quanto no de recepção das obras-de-arte, a partir do intenso processo de industrialização que lhe era contemporâneo.

A crítica da cultura da máquina continua em mais três aforismos posteriores: no §278, "Premissas da época da máquina", no §286, "O valor do trabalho" e no $\$ 288$, "Até que ponto a máquina humilha”. O $\$ 278$ é um exemplo primoroso da ourivesaria nietzschiana na sua concisão quase extrema, mas igualmente, pela profundidade que o sismógrafo nietzschiano pode alcançar. Comecemos por ele, pois vale a pena reproduzi-lo na íntegra: "a imprensa, as máquinas, a ferrovia, o telégrafo são premissas, cuja conclusão milenar ninguém ousa ainda tirar” (KSA, 2, p. 674). Aqui, a acuidade psicológica de Nietzsche se mostra em pelo menos dois aspectos importantes: o primeiro, ao lembrar-nos que estas conquistas da modernidade tecnológica de sua época são apenas premissas, uma espécie de primeiro passo, pois não se poderia medir a extensão e a capacidade da inteligência humana; o segundo por desconfiar de que não se poderia prever as profundas transformações e modificações que o progresso técnico iria alcançar nos séculos que estariam por vir. O Nietzsche psicólogo e médico da civilização, se ainda vivesse entre nós, certamente estaria sorrindo ironicamente diante de seu certeiro diagnóstico.

O §286, por sua vez, tem como pano de fundo o clima de agitação operária sempre presente na Europa da época. Estamos, como se sabe, no rescaldo da experiência violenta da Comuna de Paris. A questão para Nietzsche é como julgar, avaliar, o trabalho? O que é "justo" e "meritório" neste campo, de tal modo que o trabalhador possa receber um salário "justo"? A resposta de Nietzsche reitera uma questão já tocada em minhas 
observações anteriores, a da utilidade das ações humanas, assim como a das relações entre justiça e utilidade, as quais agora merecem um breve comentário. ${ }^{5}$

Embora não seja possível assinalar com exatidão o período em que Nietzsche começa a ler a obra de Stuart Mill, certamente ele entrou em contato com as idéias do "utilitarismo" inglês bem cedo, seja pela leitura de Denken und Wriklichkeit, de Afrikan Spir, no final de 1873, seja pelas referências que se encontram na Geschichte des Materialismus, de Lange, leitura bem anterior, de 1866 (FORNARI, 2006, p. 219-220). Em outras palavras, já existe neste momento alguma familiaridade de Nietzsche com os princípios básicos apresentados em On Utilitarism, de Mill, coletânea de dois ensaios, um sobre o utilitarismo e outro sobre a justiça, que apareceram na revista Frazer's, em primeira edição, no número de dezembro de 1861. $\mathrm{O}$ argumento central de Mill rediscute a proposição da ética clássica acerca da felicidade como fim último da ação e da vida humana e o faz sustentando a necessidade de que é necessário encontrar um "princípio único" para as obrigações morais, sobre o qual a ciência da ética pode constituir-se com segurança. Entretanto, como uma ciência singular, que não pode ser equiparada em todos os aspectos às ciências da natureza, a Ética prescinde de uma "linguagem dos fins". Por isso, a norma da obrigação moral se constitui a partir da individuação de um fim último, que vincule a ação às suas conseqüências. Assim sendo, a ação justa é aquela em que se conjugam utilidade moral e princípio da máxima felicidade (reino do prazo e ausência de sofrimento) enquanto a infelicidade é presença da dor e ausência de prazer (MARTON, 1990). Prazer que não se confunde entretanto, nem com o hedonismo puro, nem com algo grosseiramente intenso como pretendia Bentham (FORNARI, 2006, p. 223).

É possível então dizer que a época da cultura da máquina, tal como Nietzsche a apresenta nestes aforismos, significa também o triunfo do utilitarismo, por meio desta excessiva valorização do trabalho. Nesta perspectiva, o valor moral do trabalho nos é dado por uma ética utilitarista. Mais ainda: o próprio território das artes, que parecia, pelo menos em parte, imune às convulsões da época - daí as esperanças depositadas no projeto de Wagner - é inteiramente invadido e ocupado pelo utilitarismo. Assim,

\footnotetext{
${ }^{5}$ Sobre a questão da justiça em Nietzsche, ver MELO, 2004.
} 
esboça-se aqui uma crítica de Nietzsche ao utilitarismo que é neste momento de sua obra ainda referida fortemente ao campo da estética, pois é apenas na medida em que os impulsos artísticos possam ainda se liberar das injunções do mundo do trabalho, que podemos ainda resistir aos processos de exploração, à formação de uma "rede de explorados", como ele afirma no $\$ 286$ do "Andarilho", acima referido.

No único aforismo de Aurora em que Nietzsche retoma esta questão, o §173, intitulado "Os apologistas do trabalho", ele retoma o tema da "dignidade do trabalho", do qual já fizera a crítica em "O Estado grego", por exemplo. Nietzsche deplora ao mesmo tempo a "glorificação" (Verheerlichung) do trabalho e sua qualificação como uma "benção" (Segen), tendo em vista certamente as transformações históricas da idéia de trabalho. Lembro aqui, mais um comentário de Löwith: "O homem deve trabalhar com o suor de seu rosto, pois sua falta o condena ao trabalho. Lei dura e maldita, o trabalho é essencialmente miséria, pena e sofrimento. $\mathrm{Na}$ Bíblia, o homem não saboreia os 'frutos' da 'benção' do trabalho, ele expia no trabalho, o crime por ter tocado no fruto proibido" (LÖWITH, 1969, p. $319)$.

Neste mesmo diapasão, movimentam-se os aforismos da Gaia Ciência dedicados ao nosso tema. O aforismo 42, por exemplo, intitulado "Trabalho e tédio" não apenas retoma questões já tratadas em "O andarilho e sua sombra", mas também estabelece uma relação com a questão do tédio (Langweile). Nietzsche parte de uma constatação de ordem geral: na civilização, busca-se o trabalho pelo salário; neste caso, o trabalho deixa de ser um meio para se constituir em um fim em si mesmo. Ora, trabalhar apenas pelo salário exclui qualquer prazer (Lust). Em oposição à regra geral, Nietzsche se refere aos três grandes contraditores desta regra: os artistas, os contemplativos e os ociosos, ou seja, aqueles que preferem estar à margem desta cultura do trabalho e que se constituem em resistências emblemáticas ao culto à máquina. Não se trata de uma recusa enfática e definitiva do trabalho, mas de uma espécie de reiteração do mundo do trabalho artesanal, um mundo no qual trabalho e prazer se encontravam ainda associados.

Mas, ainda neste mesmo aforismo, Nietzsche refere-se ao papel ambíguo e problemático do tédio, tema de longa tradição na cultura alemã (Cf. KESSEL, 2001). É a posição diante da eventual, perigosa e temida presença do tédio, que distinguirá os três contraditores acima referidos, da 
ordem geral da sociedade disciplinar, para usar a terminologia de Foucault. Para esta, o tédio é sempre um perigo, algo contra o qual devemos nos prevenir e fugir, por intermédio da "benção do trabalho". Para aqueles, ao contrário, o tédio não constitui propriamente o inimigo a atacar, pois este é propriamente o desprazer promovido pelo trabalho como fim. Assim, em vez de ser apenas um perigo a conjurar, o tédio funciona como uma espécie de aviso, de alerta, para os "espíritos inventivos". Ele assume assim, a função de um sintoma necessário que antecede o estado criativo. Ao invés de querer afastar o tédio a todo custo (este é um dos objetivos da sociedade disciplinar), é necessário aprender a suportá-lo, de tal modo que ele possa se tornar um motor da criação. Trata-se, enfim, de destacar a função criadora do tédio, retirando-o assim do lugar comum de produtor de patologias, quando associado à melancolia, tal como preconizava certa psiquiatria da época. ${ }^{6}$

Esta mesma relação, que reúne trabalho, prazer e tédio, reaparece bem mais adiante no livro, no aforismo 329, intitulado "Tempo livre e ócio". Este aforismo se inicia, não por acaso também, com uma crítica feroz aos Estados Unidos como o lugar, por excelência, da expressão mais alta desta nova moral do trabalho ${ }^{7}$. Lembremos, fato que Nietzsche não desconhecia, que um dos grandes arautos desta nova moral foi Benjamin Franklin, um dos mais importantes nomes da Revolução Americana e que também era calvinista, justamente a corrente protestante que mais glorificou e venerou o trabalho material, segundo, pelo menos, a famosa tese de Max Weber acerca da gênese do "espírito do capitalismo". O aforismo relembra a famosa "corrida do ouro" americana como exemplo de barbárie e selvageria, mas que revela o caráter dos americanos, em especial quando associado à "asfixiante pressa com que trabalham". Este aforismo descreve, com ironia, acidez e desprezo a figura típica do capitalista: sempre ávido por lucros, pensando sempre com o relógio, sempre com os olhos voltados para os resultados da Bolsa, incapaz de cultivar o espírito e os bons modos

\footnotetext{
${ }^{6}$ Este caráter ambíguo do tédio se encontra também claramente expresso na obra de Eugen Dühring, Das Werth des Lebens, que Nietzsche acabara de ler com entusiasmo e da qual fizera inúmeras anotações, no verão de 1875 (KSA, 8, p. 130 ss.). Conforme Nietzsche vai se afastando criticamente de Dühring, ele modifica sua posição em relação ao tédio, de tal modo que, posteriormente, este aspecto positivo quase que desaparece por inteiro.

7 Sobre o antiamericanismo de Nietzsche, ver DINER (1996), MROKOVITS (2003), LARGE (1995) e HOWARD (2010). Pretendemos desenvolver este tema em outra oportunidade.
} 
ritualizados do cotidiano. Combatendo, pelo trabalho e pelo prazer no acúmulo de riquezas, tenazmente o tédio, ele jamais se dá o prazer do ócio, palavra que Nietzsche escreve em latim, "Otium". Esta cultura produz apenas "escravos exaustos do trabalho". O "Otium" tem aqui o mesmo papel que o tédio desempenhava no aforismo anteriormente referido. Contraposto, em parte à "Müssigang" (a palavra alemã que pode ser traduzida, literalmente, por "caminhar despreocupado"), o "Otium" possui um potencial criativo valorizado pelos antigos (que desprezavam o trabalho, lembra Nietzsche no final do aforismo) que a "Müssigang” já perdeu, uma vez que passar o tempo, aproveitar o tempo livre do trabalho passou a significar "descansar" ou "distrair-se" indo à ópera. Hoje, diríamos, vamos aos shoppings centers para "passear", para "passar o tempo".

Para fechar esta sequência, lembro apenas que no Livro V da Gaia Ciência, anexado, como sabemos aos quatro primeiros livros apenas em 1886, juntamente com um "Prefácio" famoso, Nietzsche retoma o tema do trabalho como "benção". Trata-se do aforismo 359, "A vingança contra o espírito e outros motivos secretos da moral". Este aforismo diz respeito, entre outros, ao fracasso da "benção do trabalho", ao fracasso de qualquer terapia ou cura pelo trabalho, questão que retornará, sobremaneira, na Terceira Dissertação da Genealogia da Moral (CHAVES, 2007). Nietzsche quer dizer com isso, que a cultura do trabalho acaba, em última instância produzindo ressentidos e decadentes, para usarmos a terminologia que se imporá no terceiro período de seu pensamento.

Como podemos ver, o tema do trabalho e sua crítica nos escritos da segunda fase do pensamento de Nietzsche envolvem, em níveis diferentes de complexidade, os campos da estética, da ética e da política. Eles prolongam algumas análises já feitas anteriormente, mas, ao mesmo tempo, deslocam as questões para uma minuciosa observação do valor do trabalho nas sociedades capitalistas da era industrial. Esta observação mostrará a Nietzsche o quanto a esfera da arte foi totalmente invadida pela elevada valoração moral do trabalho, de tal modo que a criação e a recepção das obras de arte se modificam radicalmente. É possível pensar que a crítica de

\footnotetext{
8 Nietzsche retoma aqui as indicações já feitas em "O estado grego", que desde o seu primeiro parágrafo se refere à permanência do trabalho escravo nas sociedades modernas, para, entre outros, ironizar 0 modo como nos referimos ao papel da escravidão entre os antigos, como se entre nós, não houvesse mais escravos. (KSA, 1, p. 764; CAVALCANTI, 2007, p. 123).
} 
Nietzsche ao capitalismo se inscreve ainda, de algum modo, na linhagem do que se denomina de "anti-capitalismo romântico" (LÖWY, 1990), na medida em que ele desconhecia, como o afirma Horkheimer (1937), obviamente inspirado em Marx, o caráter emancipatório do trabalho. As indicações de Nietzsche nos aforismos aqui analisamos dão razão a Horkheimer, na medida em que ele sempre vai considerar como forma de resistência ao trabalho na época das máquinas algumas formas de "ócio", em especial aquele que ainda pode impulsionar a criação artística. Mas, como o próprio Horkheimer também o afirma, desta vez considerando-o um precursor de Freud, "Nietzsche analisou o espírito objetivo de sua época, a constituição psíquica da burguesia" (HORKHEIMER, 1937, p. 408). Também neste caso, os aforismos que analisamos dão razão a Horkheimer. 


\section{Referências:}

CAVALCANTI, A. H. "Arte da experimentação: política, cultura e natureza no primeiro Nietzsche", in: Transformação, 30 (2), 2007.

CHAVES, E. "Nietzsche e os destinos da 'arte de curar"'. In PEREZ, D. O. (Org.). Os filósofos e a questão da cura. São Paulo: Escuta, 2007.

DINER, D. America in the eyes of the Germans: an essay on anti-americanism. Princenton: Markus Wiener Publishers, 1996.

FORNARI, M. C. La morale evolutiva del gregge. Nietzsche legge Spencer e Mill. Pisa: Edizioni ETS, 2006.

HORKHEIMER, M. "Bemerkungen zu Jaspers' Nietzsche", in: Zeitschrift für Sozialforschung. Paris: Félix Alcan, Band VI, 1937.

HOWARD, T. "Friedrich Nietzsche, Religion and America", in: Zeitschrift für Neuere Theologiegeschichte. Band 17, Heft 2, 2010.

KESSEL, M. L. Zum Umgang mit Zeit und Gefühlen in Deutschland vom späten 18. bis zum frühen 20. Jarhhunderts. Göttingen: Wallstein, 2001.

LARGE, D. "Nietzsche and the figure of Columbus", in: Nietzsche-Studien, Band 24, 1995.

LÖWITH, K. De Hegel a Nietzsche. Paris: Gallimard, 1969.

LÖWY, M. Romantismo e messianismo. São Paulo: Perspectiva, 1990.

MARKOVITS, A. S. "European Anti-Americanism: Past and Present of a Pedigreed Prejudice". Aula inaugural no Karl W. Deutsch Collegiate Professorship, em 24.09.2003, (Ann Arbor, Michigan). Disponível em www.lsa.umich.edu/UofM/Content/german. Acesso em 13/01/2011.

MARTON, S. Nietzsche. Das forças cósmicas aos valores humanos. São Paulo: Brasiliense, 1990.

MELO, E. R. Nietzsche e a justiça. São Paulo: Perspectiva, 2004.

NIETZSCHE, F. Kritische Studienausgabe. Berlin/München/New York: DTV/de Gruyter, 1989.

. O nascimento da tragédia. Tradução de Jacó Guinsburg. São Paulo: Companhia das Letras, 1992.

. Humano, demasiado humano II. Tradução de Paulo César Souza. São Paulo: Companhia das Letras, 2008.

. A gaia ciência. Tradução de Paulo César Souza. São Paulo: Companhia das Letras, 2002. 
Cinco prefácios para cinco livros não escritos. Tradução de Pedro Süssekind. Rio de Janeiro: Sette Letras, 1996.

Email: erna.nic@hotmail.com

Recebido: Abril/2011

Aprovado: Maio/2011 